\title{
Epoxy Casting Process and Complete Set Test for New 10 kV High Voltage Electric Energy Meter Based on All-fiber Optical Current Transformer
}

\author{
Fuli Yang ${ }^{1}$, Lujun Zhang ${ }^{2}$ and Bin $\mathrm{Li}^{2}$ \\ ${ }^{1}$ Electric Power Research Institute of Chongqing Electric Power Company of State Grid, Chongqing, China \\ ${ }^{2}$ Chongqing Qianwei Jibao Power Equipment Co., Ltd., Chongqing, China
}

\begin{abstract}
V high voltage electric energy meter is manufactured using new full-fiber optical current transformer, model selection process scheme is proposed at all aspects, all-fiber optical current transformer is improved in combination with the existing problems found in production, and finished-products are manufactured and tested for verification by improving the epoxy casting process.
\end{abstract}

Keywords-all-fiber optical current transformer; high voltage electric energy meter; casting

\section{BACKGROUND OVERVIEW}

Currently, the power distribution network measures the electric energy through $10 \mathrm{kV}$ high voltage power metering box or electric energy metering cubicle, which means the high voltage power is measured by the access of standard low voltage $(100 \mathrm{~V}$ or $100 / \sqrt{3} \mathrm{~V})$ transformed from large voltage of high voltage and standard low voltage small current (5A or $1 \mathrm{~A})$ transformed from large current of high voltage through several high voltage electromagnetic current and voltage transformers to the electric energy meter,with its principle showm in Figure I.

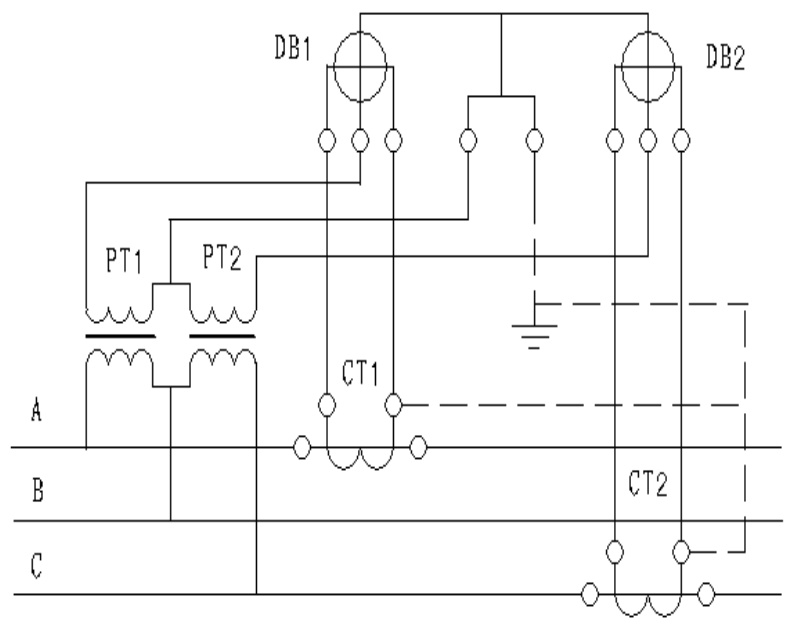

FIGURE I. MEASURING PRINCIPLE OF TRADITIONAL High VoltagE ELECTRIC ENERGY

However, there are many disadvantages in traditional electromagnetic transformer, such as frequent accidents, high energy consumption, high consumable material, poor error characteristic curve which cannot be exclusively determined, inconvenient management, difficulty in electricity larceny prevention. A new generation of full-fiber optical current transformer based on Faraday magneto optic effect is produced, which is mostly featured by its special sensing fiber at high voltage end, without the need of any other functional components to ensure no high voltage breakdown occurs, thus greatly improving the reliability of such transformer. It is gradually used to various high voltage and extra high voltage power grids.

With the development of electronic, digital and communication technology, the full-fiber optical current transformer can be used to the $10 \mathrm{kV}$ power grid reduced from the original power grid of above $110 \mathrm{kV}$ due to its increasingly growing accuracy, even $0.2 \mathrm{~s}$. For example, the full-fiber optical current transformer researched and developed by Shanghai Kangkuo Optical Communication Technology Co., Ltd., with voltage class of $10 \mathrm{kV}-1200 \mathrm{kV}$, current measuring range of $25 \mathrm{~mA}-7500 \mathrm{~A}$, measurement accuracy (IEC) of $0.2 \mathrm{~S}$, protection accuracy (IEC) of 5P30, which completely satisfies the operating requirements of $10 \mathrm{kV}$ high voltage electric energy meter.

As shown in FigureII, its principle is that the light from light source is polarized by polarizer via coupler, is divided into two beams with polarization direction mutually perpendicular after the phase modulation via modulator and gets into the sensing optical fibre via transmission optical fibre and is superposed coherently at photoelectric detector at end of sensing optical fibre.

When there is no current in primary conductor, the relative propagation speed of the two beams of light is equal, which means there is no phase difference when they are superposed coherently at the detector; when it is energized, the propagation speed of the two beams of light changes under the action of magnetic field around the live conductor to cause phase difference, thus making the light intensity at the detector change accordingly. The current of primary conductor can be measured by measuring the light intensity.

The casting process of the $10 \mathrm{kV}$ high voltage electric energy meter based on the full-fiber optical current transformer is explored and analyzed in this document. 


\section{CASTING Process OF EPOXY Resin}

The epoxy resin is featured by the excellent electrical insulation property, high mechanical strength, heat resistance and resistance to chemical attack, good curing shrinkage rate and coefficient of linear expansion, good dimensional stability and manufacturability. Since the $1980 \mathrm{~s}$, it has been used for the transformer, instrument transformer, insulator and other electrical products as main insulating materials, with its voltage rising from $10 \mathrm{kV}$ and below to $35 \mathrm{kV}$.

Its main processing method is casting, which means pouring the epoxy resin formula materials to the assembled work-piece mold and demold to get the finished product after the curing reaction. Such process is of integral dry insulation type, the dominant insulation method to realize the miniaturization, lightweight and low noise of electrical product and has experienced the process of development of normal pressure casting, partial vacuum casting, full vacuum casting and automatic pressure gelation (APG). We adopt the popular full vacuum casting process and summarize an effective process and get good application result in the sensing high voltage electric energy meter, with the advantages that the preparation, mixing and casting are under vacuum state to minimize the bubbles in the casted products, improve the product electrical insulation and mechanical property, improve the product yield and reduce the product cost and labor intensity. Its process is shown in Figure III:

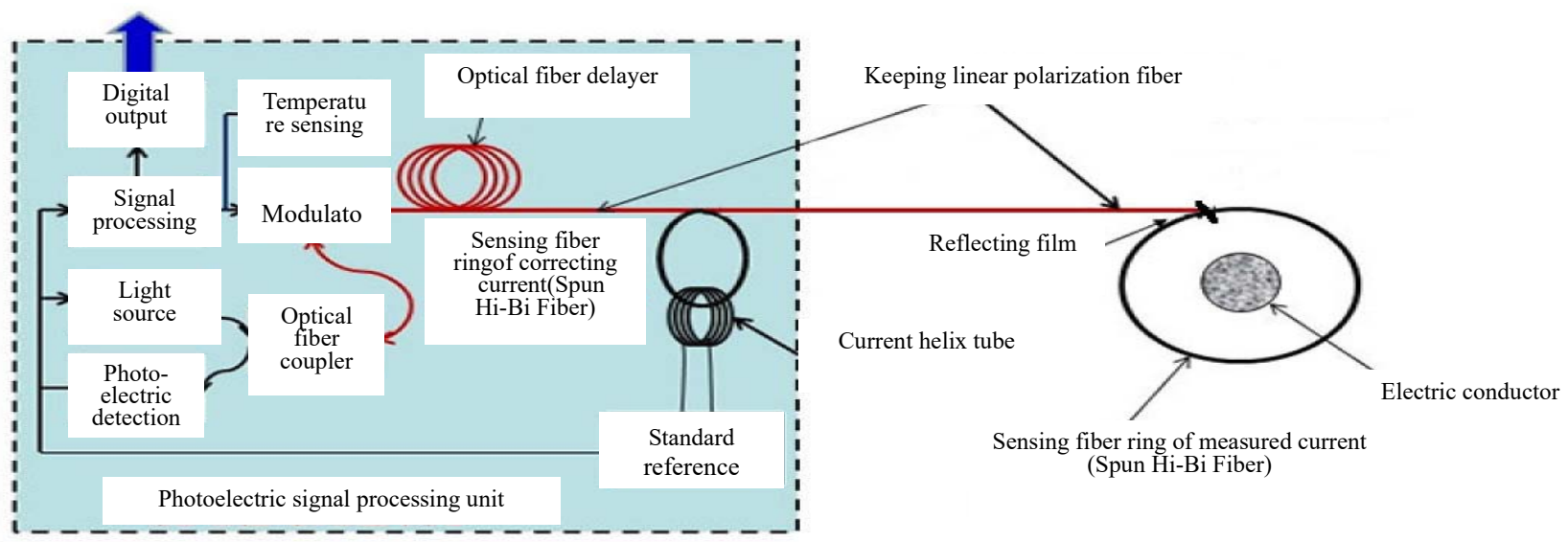

FIGURE II. Principal Block Diagram of FUll-FIBER OPTICAL CURRENT TRANSFormer

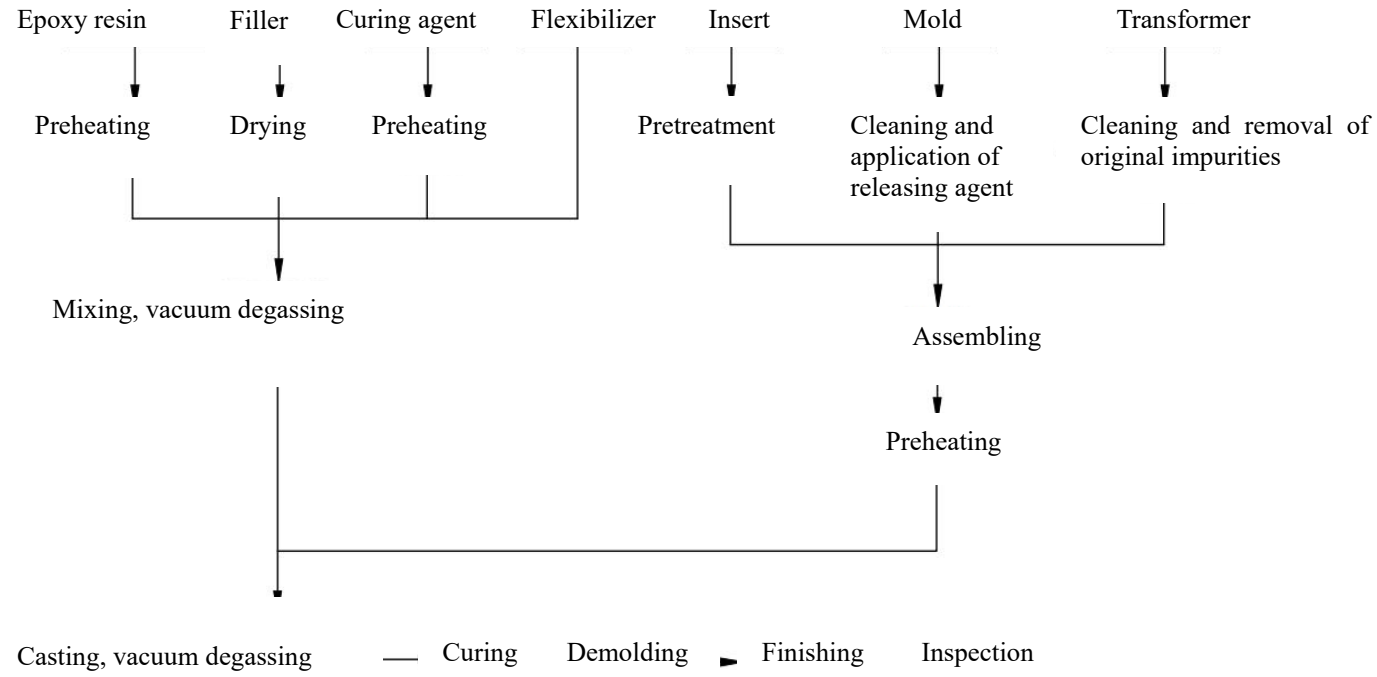

FIGURE III. FULL-VACUUM CASTING PROCESS

We consider that as long as the full-fiber optical current transformer is reasonably designed, with high quality devices, it can satisfy the requirements for test and use after the epoxy casting. 


\section{A. Processing of Full-fiber Optical Current Transformer}

To fit the currently manufactured high voltage electric energy meter, the supplier furnished full-fiber optical current transformer sensing ring has the same size as the coil of the existing electromagnetic transformer to make it convenient to replace without opening mold. The output analog signal of the full-fiber optical current transformer can be measured by measurement unit.

The existing various full-fiber optical current transformers operate under $-40^{\circ} \mathrm{C}-+70^{\circ} \mathrm{C}$, and cures under $120^{\circ} \mathrm{C}$ during the epoxy casting, which may affects its property and even cause damage to the full-fiber optical current transformer. We make the following improvements to the common full-fiber optical current transformer:

1) Sensing fiber ring: the ring was covered by a layer of aluminum case for electrical protection, but now covered by heat resistant plastic and sealed to prevent the high voltage magnetic field from being affected by metal materials in use and the prevent the optical fiber from being damaged by the epoxy resin flowing into the ring during the casting;

2) The exposed tail fiber is installed with $4 \mathrm{~mm} O D$ teflon casing resisting temperature of $-40{ }^{\circ} \mathrm{C}-+200^{\circ} \mathrm{C}$ to avoid the effect of high temperature and stress on the tail fiber during the casting.

\section{B. Preheating}

The epoxy resin castable, a formula system containing epoxy resin, curing agent, functional aids, inorganic powder filler, will absorb moisture in the air during the transportation and storage, thus reducing the product insulation. It shall be preheated to improve the fluidity.

1) Drying of silica powder: add the silica power to the silica power drying tank for drying more than 7 hours under $120^{\circ} \mathrm{C}$. Continuously stir and vacuumize during the drying to ensure the vacuum degree of $1000 \mathrm{~Pa}-20000 \mathrm{~Pa}$;

2) Preheating of epoxy resin: we preheat the metal bucket in which the epoxy resin is put to the heating furnace using BPA epoxy resin E-39D for heating more than 5 hours under $100^{\circ} \mathrm{C}-120^{\circ} \mathrm{C}$;

3) Preheating of curing agent: put the metal bucket in which the curing agent is put to the heating furnace for heating more than 5 hours under $120^{\circ} \mathrm{C}-130^{\circ} \mathrm{C}$;

4) Preheating of mold: apply releasing agent on the surface of mold, fix the semi-finished transformer to the mold as per process, check the insulation resistance and other electrical performance, put the mold in the drying oven for heating more than 4 hours under $120^{\circ} \mathrm{C}$.

\section{Mixing Materials}

Premix (blend) or finally mix pretreated raw materials. The premixing is to automatically weight epoxy resin, curing agent and intake them into pre-mixing tank according to a certain mix proportion, let them fully mixed, vacuumed and de-aerated, it is divided into burdening of epoxy resin and burdening of curing agent; the final mixing is to import bi-component mixtures of de-aerated epoxy resin + silica powder and curing agent + silica powder into final-mixing tank through auto-weighing, and further mix evenly to castable under constant temperature and vacuum.

1) Firstly heat pre-mixing tank and keep tank temperature up to $85^{\circ} \mathrm{C}-90^{\circ} \mathrm{C}$;

2) Add epoxy resin, silica powder to pre-mixing tank A and mix them for $10 \mathrm{~min}$, after being stirred evenly, vacuumize (230 Pa-300 Pa) and continuously mix, with duration no less than $2 \mathrm{~h}$; the pre-mixing tank $\mathrm{B}$ is added with curing agent, flexibilizer and silica powder, mixed for $10 \mathrm{~min}$, after being stirred evenly, vacuumize (230 Pa-300 Pa) and continuously mix, with duration no less than $2 \mathrm{~h}$;

3) Stop blending materials of pre-mixing tank and release pressure, and successively add materials of pre-mixing tank A and that of pre-mixing tank B to final mixing tank, blend and vacuumize (230 $\mathrm{Pa}-300 \mathrm{~Pa})$, with duration of $30 \mathrm{~min}$;

4) Accelerant is added to final mixing tank, and vacuumize (230 Pa-300 Pa) about $10 \mathrm{~min}$.

\section{Casting}

After the completion of premixing materials, preheated die set can be placed in Casting tank of $110^{\circ} \mathrm{C} \pm 5^{\circ} \mathrm{C}$, vacuumize to $200 \mathrm{~Pa}$, it is poured manually, according to the complexity of cavity of die set and the advantages and disadvantages of Casting technology, in general, the flow can be artificially controlled to $1.5-2 \mathrm{~kg} / \mathrm{min}$, or subject to not obstruct gas vent, so that the die set is fully filled with castable; After the completion of Casting, continuously vacuumize (200Pa) for 30 min.

\section{E. Solidifying}

1) The poured die set is placed to drying oven, and it shall be heated and solidified according to curing temperature-time curve required by materials, the solidification processes are divided into initial and post solidifications, low-temperature gel processing is used during the former stage to reduce internal stress and inner cavities due to volume shrinkage, firstly solidify under temperature of $100^{\circ} \mathrm{C} \pm 5^{\circ} \mathrm{C}$ for $1.5 \mathrm{~h}$, and then in temperature of $120^{\circ} \mathrm{C} \pm 5^{\circ} \mathrm{C}$ for $2.5 \mathrm{~h}$.

2) Perform hot rapid demoulding during initial solidification, open die set and take out casting body, with burr flash and feeding removed, move it to drying oven for post solidification, the temperature is $120^{\circ} \mathrm{C} \pm 5^{\circ} \mathrm{C}$ that raises steadily, and it takes $12 \mathrm{~h}$. After the completion of solidification, take out the finished product after its temperature has been naturally lowered to ambient temperature with the oven, so as to fully release internal stress and avoid cracks.

\section{F. Key Points of Technological Process}

\section{1) Strict temperature control}

The preheating, mixing and casting temperature for cast material of epoxy resin shall be controlled precisely in strict accordance with technological parameters, or it will affect casting quality. It shall be heated slowly and evenly, or local materials will be degenerated and damaged due to too high 
temperature. It is cold in winter, so the tanks and pipes shall be preheated during proportioning.

\section{2) Mixing, blending and de-aerating duration}

The time parameter of this technological process depends on the sequence and mobility of proportioning and feeding, and it is generally controlled at 3-4 h. The final mixing shall not take too long, which shall be $30-45 \mathrm{~min}$, or material viscosity will grow rapidly over time, with casting time forced to be reduced, thus affecting the speed of material flow and casting quality. The quality of de-aerating will be critical to the number of bubbles during casting, less bubbles means higher quality. At present, thin film de-aerating method with an optimal degasifying effect is widely used.

\section{3) Casting process}

Before casting, air pressure of casting tank shall be slightly lower than that of final mixing tank to prevent materials ejecting reversely. The casting speed is generally controlled at $1.5-2 \mathrm{~kg} / \mathrm{min}$ or subject to not obstruct gas vent, the castable shall be poured and put into Casting gate of die set continuously and slowly, incomplete filling is easily formed at the Casting gate after solidifying because it is too fast, while it is easy for air pockets or large incomplete filling formed internally after solidifying because it is too slow.

\section{4) Solidifying}

The Casting gate of die set shall be checked within about 1-2 $\mathrm{h}$ during solidifying, namely before gel processing, it shall be supplemented in case of incomplete filling, which shall not be supplemented $4 \mathrm{~h}$ after solidifying.

The solidifying process has three time periods when potential internal stress is easily formed:

a) Initial solidification: the potential internal stress is mainly formed during the stage, and a higher temperature of initial solidification means a larger internal stress formed by casting product.

b) Stage of hot rapid demoulding: the casting product is generally required to be put to drying oven within 10 min after demoulding, and a longer stay at ambient temperature means faster temperature drop and a larger internal stress. Avoid taking out the casting product under a major mechanical impact during demoulding.

c) Cooling stage: after the completion of solidifying process, take out the finished product after its temperature has been naturally and slowly lowered to ambient temperature with the oven.

\section{TEST OF FInISHed CASTING PRODUCT}

\section{A. Test of All-fiber Optical Current Transducer}

The comparison test for accuracy of all-fiber optical current transducer has been performed before and after casting to verify the influences of casting on the transducer, data of test parameter is shown in Table 1:

It can be concluded from table below that the level of improved all-fiber optical current transducer can reach to 0.2 before and after casting, with casting requirements met.
TABLE I. ACCURACY TEST OF COMPLETE SET

\begin{tabular}{|c|c|c|c|c|}
\hline & & $\begin{array}{c}\text { Phase A } \\
(\%)\end{array}$ & $\begin{array}{r}\text { Phase C } \\
(\%) \\
\end{array}$ & $\begin{array}{l}\text { Combined } \\
\text { Phase (\%) }\end{array}$ \\
\hline \multirow{6}{*}{$P F=1$} & $120 A$ & -0.15 & 0.35 & 0.30 \\
\hline & $100 A$ & -0.05 & 0.20 & 0.25 \\
\hline & $50 A$ & / & / & 0.10 \\
\hline & $10 A$ & 1 & 1 & 0.00 \\
\hline & $5 A$ & -0.25 & 0.30 & -0.20 \\
\hline & $1 A$ & 1 & 1 & -0.15 \\
\hline \multirow{6}{*}{$P F=0.5 \mathrm{~L}$} & $120 A$ & 0.10 & 0.30 & 0.30 \\
\hline & $100 \mathrm{~A}$ & 0.20 & 0.10 & 0.20 \\
\hline & $50 A$ & 1 & / & -0.20 \\
\hline & $20 A$ & 1 & / & 0.20 \\
\hline & $10 A$ & -0.45 & 0.45 & 0.25 \\
\hline & $2 A$ & 1 & 1 & 0.15 \\
\hline \multirow{6}{*}{$P F=0.8 C$} & $120 A$ & & & 0.20 \\
\hline & $100 A$ & & & 0.15 \\
\hline & $50 A$ & 1 & / & 0.15 \\
\hline & $20 A$ & 1 & 1 & -0.25 \\
\hline & $10 A$ & & & -0.20 \\
\hline & $2 A$ & 1 & I & 0.10 \\
\hline
\end{tabular}

\section{B. Complete Set Test}

The standard unit of high voltage electric energy meter that is qualified by measurement standard is used to test measuring accuracy of new 10kVhigh voltage electric energy meter, with measuring accuracy of level 0.1 , it can also be used to entirely check level 0.5 Shigh voltage electric energy meter and test overall metering error of traditional HV metering device.

The new $10 \mathrm{kV}$ high voltage electric energy meter to be checked has a rated voltage of $10 \mathrm{KV}$, a rated current of $100 \mathrm{~A}$, and active pulse constant of $640 \mathrm{imp} / \mathrm{MWh}$, the measured vale of positive active energy error is shown in Table 2, with its accuracy level up to $0.5 \mathrm{~S}$.

TABLE II. ACCuRACy TeSt OF All-Fiber Optical CURRENT TRANSDUCER

\begin{tabular}{|c|c|c|c|c|c|c|c|c|}
\hline & \multicolumn{3}{|c|}{$\begin{array}{c}\text { Ratio Error under Rated } \\
\text { Current 100A (\%) } \\
\pm \%\end{array}$} & \multicolumn{3}{c|}{$\begin{array}{c}\text { Phase Error under Rated } \\
\text { Current 100A (\%) } \\
\pm(\text { ) }\end{array}$} \\
\hline & 5 & 20 & 100 & 120 & 5 & 20 & 100 & 120 \\
\hline $\begin{array}{c}\text { Before } \\
\text { casting }\end{array}$ & 0.48 & 0.24 & 0.12 & 0.12 & 20 & 9 & 6 & 5 \\
\hline $\begin{array}{c}\text { After } \\
\text { casting }\end{array}$ & 0.54 & 0.30 & 0.14 & 0.12 & 22 & 9 & 6 & 6 \\
\hline
\end{tabular}

\section{CONCLUSIONS}

The experimental results demonstrate that the new $10 \mathrm{kV}$ high voltage electric energy meter based on all-fiber optical current transducer can ensure accurate metering and insulating property of products and meet design requirements through strict control of casting process and the improvement of the transducer.

\section{REFERENCES}

[1] Haijun Wu. Epoxy Resin Vacuum Casting Process and Announcements [J]. Transformer, 2000, 37 (5).

[2] Henian Qiu.The composition of epoxy resin vacuum casting technology chain[C].Nanjing:Epoxy resin application techonlogy society of China.2009. 